\title{
Mechanical Property Testing of Hydrogenated Zirconium Irradiated with Electrons
}

\author{
Viktor N. Kudiiarov * (D), Vitaliy V. Larionov and Yuri I. Tyurin \\ Division for Experimental Physics, School of Nuclear Science \& Engineering, National Research Tomsk \\ Polytechnic University, Tomsk 634050, Russia; lvv@tpu.ru (V.V.L.); tyurin@tpu.ru (Y.I.T.) \\ * Correspondence: viktor.kudiiarov@gmail.com; Tel.: +7-913-870-0989
}

Received: 22 February 2018; Accepted: 20 March 2018; Published: 23 March 2018

\begin{abstract}
The mechanical properties of the hydrogenated zirconium alloy $\mathrm{Zr}-1 \mathrm{Nb}$ are studied under different conditions for hydrogen removal by an electron beam and thermal heating. The mechanical testing of zirconium samples is analyzed during hydrogenation and irradiation with a low energy electron beam. The plasticity of the samples is shown to be increased during the radiation stimulation of hydrogen removal from zirconium by even a weak electron beam. In this case, the tensile strength (ultimate strength) is practically not changed.
\end{abstract}

Keywords: zirconium alloys; deformation of samples; hydrogenation and desorption; activation degassing energy; electron irradiation

\section{Introduction}

Zirconium alloys are used in high-tech units and equipment of atomic power stations as coatings for the elements in the nuclear core of thermal neutron reactors such as fuel-element cans, fuel assemblies, channels, remote grids, etc. [1,2]. The use of zirconium alloys is limited by the problems connected with the dissolution of hydrogen [2-4] formed in the nuclear core due to nuclear reactions. The accumulation of hydrogen in metal leads to changes in its strength and other characteristics. An increase in the concentration of local stresses in any region of material leads to the formation and growth of dislocations and cracks, which worsens the mechanical properties of these alloys. In addition, hydrogen embrittlement occurs due to the formation of hydrogen subsystems such as zirconium hydrides. This process depends on the amount of hydrogen dissolved in the metal lattice and the temperature variation rate. Durability and reliability of units is defined by the capability of a material from zirconium alloys to withstand mechanical loads and irradiation during hydrogenation [1-5]. The solubility of hydrogen in zirconium alloys does not exceed $1 \times 10^{-5} \mathrm{wt} \%$ at room temperature and is equal to $2 \times 10^{-2} \mathrm{wt} \%$ at the operating temperature $\left(\sim 350^{\circ} \mathrm{C}\right)$. If the solubility limit of hydrogen is exceeded, hydride phases are formed in zirconium alloys, which leads to the embrittlement effect, since hydrides have a much lower plasticity compared with zirconium. In addition, hydrides in the zirconium matrix can serve as places for the formation of cracks with subsequent opening [4] and open fracture. As a rule, a hydride layer $50-100 \mu \mathrm{m}$ in thickness is formed on the external surface of the product (for example, fuel-element claddings), the thickness of which depends on the level of hydrogenation [6-12]. Studies [8,9] have shown that when hydrogenation takes place at a temperature that is lower than the threshold temperature, a hydride layer is formed in the Zircaloy-2 and Zircaloy-4 zirconium shells. If hydrogenation takes place at a temperature that is above that of the threshold, the layer is not formed.

Another factor that has an effect on the hydrogenation of zirconium alloys is the surface condition, namely, an oxide film [13-15]. In the presence of a solid thin oxide film on the surface, zirconium alloys slightly absorb hydrogen even at high temperatures [16]. The stress distribution in the plastic 
deformation zone was studied in [17]. Diffusion of hydrogen in zirconium as a function of temperature was described in [18]. The size of the plastic zone and the corresponding stress were discussed in [19]. Diffusion calculations were carried out in [20]. Nonirradiated fuel-element claddings ( $\mathrm{Zr}-1 \mathrm{Nb}$ alloy) as a function of temperature were studied in [21]. The value of offset yield strength was determined for the case when hydrogenated zirconium was not subjected to external stresses in the works [22,23]. The $\mathrm{Zr}$-H state diagram [24] has shown that the main hydride phase is $\alpha$-zirconium during the slow cooling of hydrogenated zirconium samples. The influence of external stress was studied in [25]. In the absence of external stresses, the hydrogen concentration in the $\alpha$-phase of hydrogenated zirconium was determined in [17]. A delayed hydride cracking calculation model was proposed for the stationary model $[25,26]$. The effect of temperature on strength characteristics was studied in a number of other papers [17,27-31], including the effect of isotopic composition [32].

There are several ways to solve this problem such as application of coatings, high-current beam irradiation, and creation of low-temperature conditions for hydrogen release [5,33,34]. In many cases, hydrogenated products (for example, fuel-element claddings) are deformed, which leads to the formation of pores, cracks, and other defects $[1,35]$. The influence of hydrogen release on the mechanical properties of zirconium alloys remains unclear.

The purpose of this work is to study the mechanical properties of $\mathrm{Zr}-1 \mathrm{Nb}$ zirconium alloy samples hydrogenated and irradiated with electrons to strengthen and change their mechanical properties using stimulated gas release.

\section{Materials and Preparation of Samples}

Two types of $\mathrm{Zr}-1 \mathrm{Nb}$ zirconium alloy samples with dimensions of $150 \mathrm{~mm} \times 8 \mathrm{~mm} \times 2 \mathrm{~mm}$ and $50 \mathrm{~mm} \times 50 \mathrm{~mm} \times 0.7 \mathrm{~mm}$ were used for the study. The first type of samples was tested using a tensile machine. The samples were cut from a zirconium sheet perpendicular to the rolled sheet using spark cutting and had a form that corresponded to ISO 6892-84. The surface of the samples was mechanically ground to remove surface contaminants. The surface stresses and defects were eliminated by annealing in a vacuum at a pressure of $1 \times 10^{-5} \mathrm{~Pa}$ at a temperature of $580^{\circ} \mathrm{C}$ for $180 \mathrm{~min}$. The microstructure study of samples with an optical microscope showed that the inclusions of the second phases in the alloy matrix are distributed evenly, without clusters, and have a rounded shape. Studies in polarized light have shown that all samples after final annealing have a recrystallized structure with an equiaxed shape of the grains. The average measured grain size was within $2.8-3.7 \mu \mathrm{m}$. The minimum grain size was $0.6-1.4 \mu \mathrm{m}$, and the maximum grain size, taking into account their conglomeration due to the close polarization of neighboring grains, was $8.1-10.2 \mu \mathrm{m}$. It should be noted that there is a crystallographic texture in the direction 002 associated with the direction of rolling.

The samples with the dimensions of $150 \mathrm{~mm} \times 8 \mathrm{~mm} \times 2 \mathrm{~mm}$ were hydrogenated using a PCI "Gas Reaction Controller" complex (Advanced Materials Corporation, Pittsburgh, PA, USA) and the Sieverts method at a temperature of $600{ }^{\circ} \mathrm{C}$ and a pressure of $2 \mathrm{~atm}$ during continuous heating (to determine the threshold temperature of hydrogen absorption). After that, the samples were cooled at a rate of $2{ }^{\circ} \mathrm{C} / \mathrm{min}$ to room temperature. The hydrogen content in the zirconium alloy samples was varied from 0.035 to $0.07 \mathrm{wt} \%$ with an accuracy of up to $\pm 0.0001 \mathrm{wt} \%$.

The other samples with the dimensions of $50 \mathrm{~mm} \times 50 \mathrm{~mm} \times 0.7 \mathrm{~mm}$ were saturated in the $0.1 \mathrm{~N}$ sulfuric acid solution for $20 \mathrm{~h}$ at an electrolysis current of $0.03 \mathrm{~A} / \mathrm{cm}^{2}$ and room temperature with the use of a mass spectrometer and an electron gun [36]. The effect of accelerated electrons on the release of hydrogen from the samples was investigated in the energy range of 10-120 keV. The beam current can be changed from $1 \mu \mathrm{A}$ to $1 \mathrm{~mA}$. A movable tungsten foil that blocks the sample from direct electron irradiation of its surface is located in the vacuum chamber in front of the sample. The beam can be moved over the area of the sample, using an external magnetic field. The setup can investigate both the hydrogenated electrolytically and simultaneously irradiated samples and the samples preliminarily saturated by the Sieverts method to be irradiated with electrons. A number of samples were dehydrogenated after irradiation with electrons. 
Radiation-stimulated hydrogen release (RSHR) from zirconium ( $\mathrm{Zr}-1 \mathrm{Nb})$ was studied after electrolytic and gas saturation. The saturated zirconium samples were irradiated with an electron beam with a current density of up to $1000 \mu \mathrm{A} / \mathrm{cm}^{2}$. The irradiation time was up to $300 \mathrm{~s}$. The $\mathrm{Zr}-1 \mathrm{Nb}$ zirconium alloy saturated in the same solution for the same period of time and in the same electrolysis current was heated for thermally-stimulated hydrogen release (TSHR), using the same setup.

In the electrolytic cell, hydrogen saturation was up to $0.005 \mathrm{wt} \%$. The use of two methods for saturation allows us to correctly compare gas release due to electron irradiation. The absolute hydrogen concentration was determined in the investigated zirconium alloys, using the RHEN 602 analyzer (LECO, Saint Joseph, MI, USA).

The surface microhardness of the zirconium alloys was measured using a KB5 device by Pruftechnik, Germany (load was $30 \mathrm{~g}$, holding time was $10 \mathrm{~s}$ ). A Vickers diamond pyramid with an interfacial angle of $136^{\circ}$ was used as an indenter. The Nanotest 600 (Micro Materials, Great Britain, UK) device was used to additionally check microhardness and nanohardness. In the first case, the maximum load of the indenter was $300 \mathrm{mN}$ and up to $80 \mathrm{mN}$ in the second case. The tip of the indenter in a scanning microscope was directly measured. The diagonal of the imprint was about $3.6 \mu \mathrm{m}$. The penetration depth was analyzed versus the applied force during loading and unloading, using the Oliver and Pharr method [37]. The DFM 5000 (Com-Ten Industries, Pinellas Park, FL, USA) testing machine was used for the mechanical tests before and after irradiation and hydrogenation. The shape and the dimension ratio of the samples corresponded to ISO 6892-84. The strain rate of the samples was $2 \mathrm{~mm} / \mathrm{min}$.

\section{Experimental Results and Discussion}

\subsection{Investigation of Gas Release from Zirconium Alloy Samples}

The release of gas during heating and irradiation was investigated with the help of a special complex equipped by the quadrupole mass spectrometer and special electron gun [8]. The mass spectrometer measured the intensity of gas release (hydrogen yield) according to spectral lines [36]. The results of thermally-stimulated and radiation-stimulated hydrogen release from a zirconium alloy after hydrogenation up to $0.07 \mathrm{wt} \%$ are shown in Figure 1.

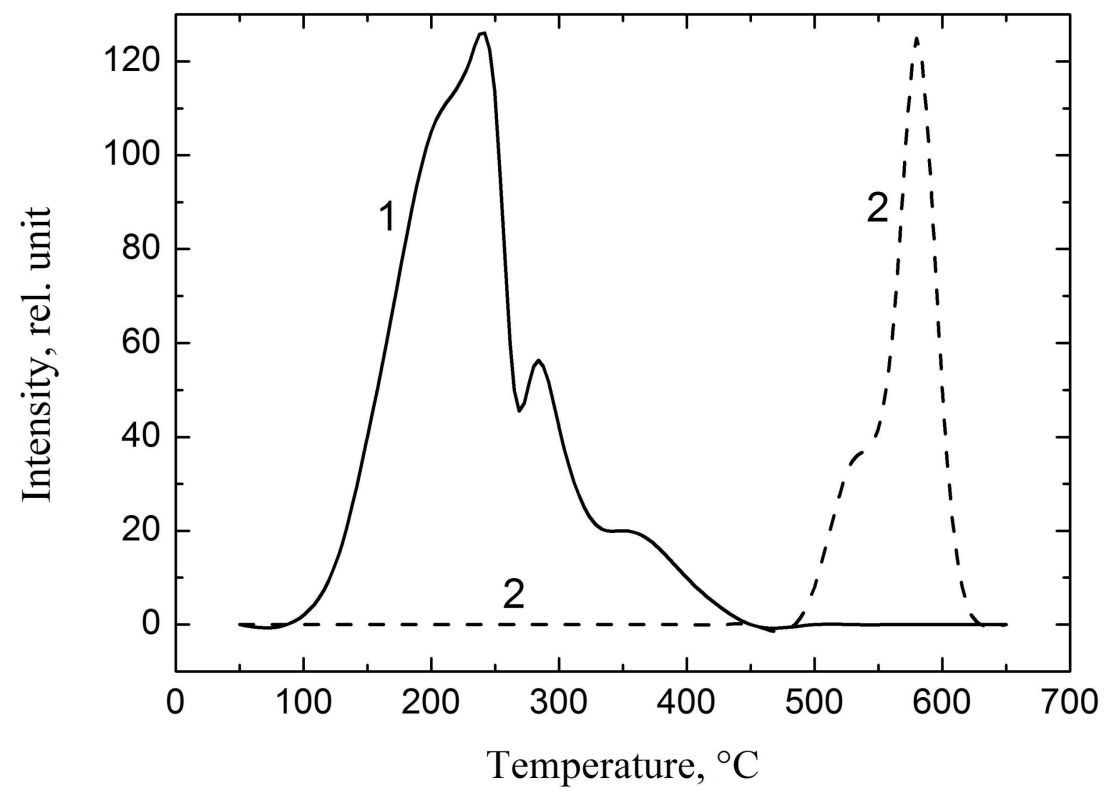

Figure 1. Radiation-stimulated (1) and thermally-stimulated (2) hydrogen release from the zirconium alloy after hydrogenation up to $0.07 \mathrm{wt} \%$. 
The value of desorbed hydrogen has been calculated and is equal to $0.06 \mathrm{wt} \%$ for radiation-stimulated hydrogen release and is equal to $0.03 \mathrm{wt} \%$ for thermally-stimulated hydrogen release. As can be seen from Figure 1, the displacement of RSHR is $\Delta \mathrm{T}_{\mathrm{Zr}}=318^{\circ} \mathrm{C}$ in comparison with TSHR. The activation energy of the hydrogen yield for linear heating of the sample can be determined by the Redhead formula [37]:

$$
E_{d}=k T_{\max }\left(\ln \frac{v_{1} T_{\max }}{\beta}-3.64\right)
$$

where $\beta=\frac{d T}{d t}$ is the heating rate, $v_{1} \sim 10^{13} \mathrm{~s}^{-1}$ is the frequency desorption factor. Table 1 shows the calculation results for the yield of activation energy of hydrogen desorption during the linear thermal heating at a rate of $\sim 1 \mathrm{~K} / \mathrm{s}$ and the linear heating of the sample by an electron beam at a rate of $\sim 10 \mathrm{~K} / \mathrm{s}$.

Table 1. The activation energy of the hydrogen yield at various heating rates of zirconium alloy samples.

\begin{tabular}{cccc}
\hline Sample & $\mathrm{fi}$ (TSHR), K/s & $T_{\max }$ (TSHR), K & $E_{d}$ (TSHR), eV \\
\hline \multirow{2}{*}{$\mathrm{r}-1 \mathrm{Nb}$} & 1 & 823 & 2.5 \\
& $\beta$ (RSHR), K/s & $T_{\max }$ (RSHR), K & $E_{d}$ (RSHR), eV \\
& 10 & 505 & 1.31 \\
\hline
\end{tabular}

Electron irradiation of a zirconium alloy leads to a decrease in the amount of hydrogen penetrating into the alloy, as compared to the initial one, and it does not matter how hydrogenation is conducted (electrolytically or from the gas phase). There is a change only in the amount of hydrogen penetrating into the alloy irradiated with electrons. During electrolytic saturation this quantity is lower by 1.4-1.6 times and 2.0-2.3 times during gas saturation for the zirconium initial sample.

\subsection{Mechanical Testing}

The microhardness (Figure 2) of the initial material ( 2000-2500 MPa) and the material hydrogenated by the Sieverts method was measured using a microindentation method.

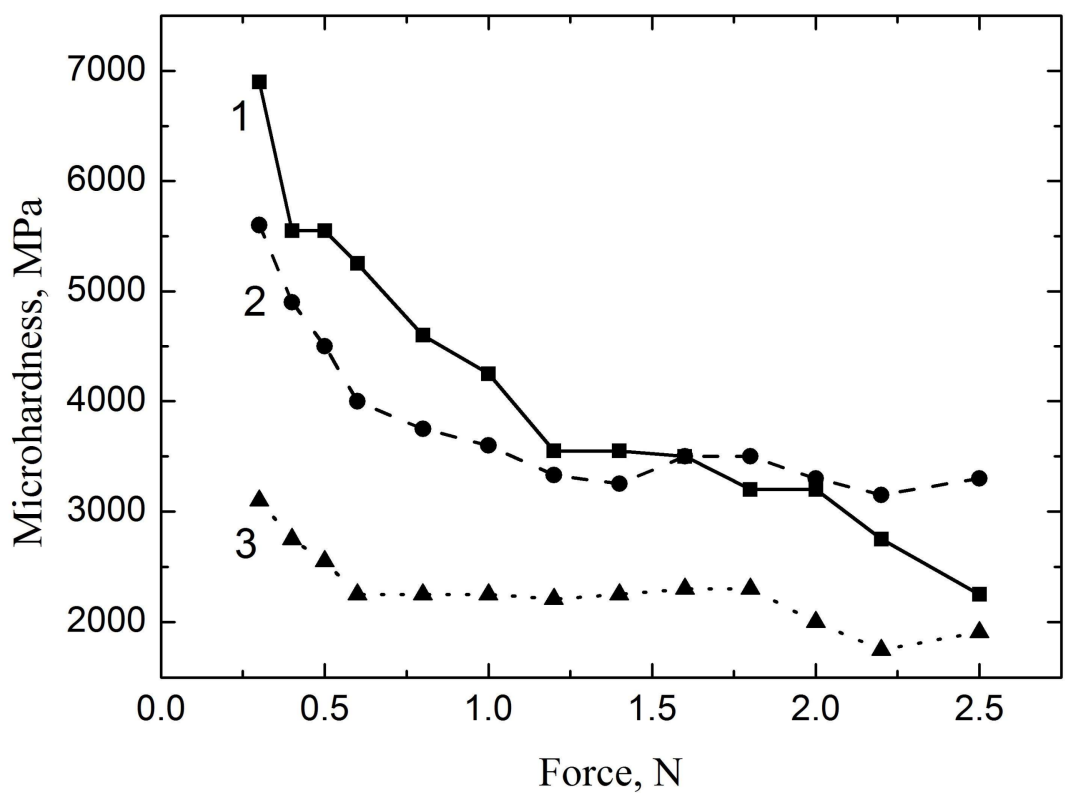

Figure 2. Microhardness of zirconium versus the load of the indenter: 1 is the hydrogenated zirconium alloy; 2 is the dehydrogenated zirconium alloy after RSHR by an electron beam; 3 is the initial (not hydrogenated) sample of the zirconium alloy. 
The measurements were conducted taking into account the recommendations given in previous studies $[38,39]$. Electron beam irradiation simultaneously leads to the removal of hydrogen and a partial increase in the microhardness (curve 2 is located higher than curve 3, Figure 2).

The electron track in the zirconium alloy $\left(\varrho=6.5 \mathrm{~g} / \mathrm{cm}^{3}\right)$ is $81 \mu \mathrm{m}$ at an accelerating voltage $\mathrm{U}=50,000 \mathrm{~V}$. Therefore, the surface layer that has a small thickness due to the small track of electrons in the zirconium alloy is strongly irradiated with electrons. The decrease in the microhardness is observed with the increase in the load of the sample (Figure 2). The microhardness of the surface after electron irradiation is decreased by up to $\sim 3000 \mathrm{MPa}$ compared with the hydrogenated sample. When the load of the indenter is $\sim 0.6 \mathrm{~N}$, the microhardness is $\sim 2200 \mathrm{MPa}$, which corresponds to the microhardness of the initial zirconium sample before hydrogenation. The microhardness of the samples after irradiation with an electron beam and hydrogenation leads to the formation of a layer on the zirconium surface with a lower microhardness equal to $2800 \mathrm{MPa}$. This is connected with the fact that strongly bound hydrogen is released at lower temperatures during irradiation, while the hydrogen adsorbed on the surface of the zirconium sample is mainly released during normal heating.

Figure 3 shows that the increase in the saturation time leads to an increase in the nanohardness of the alloy.

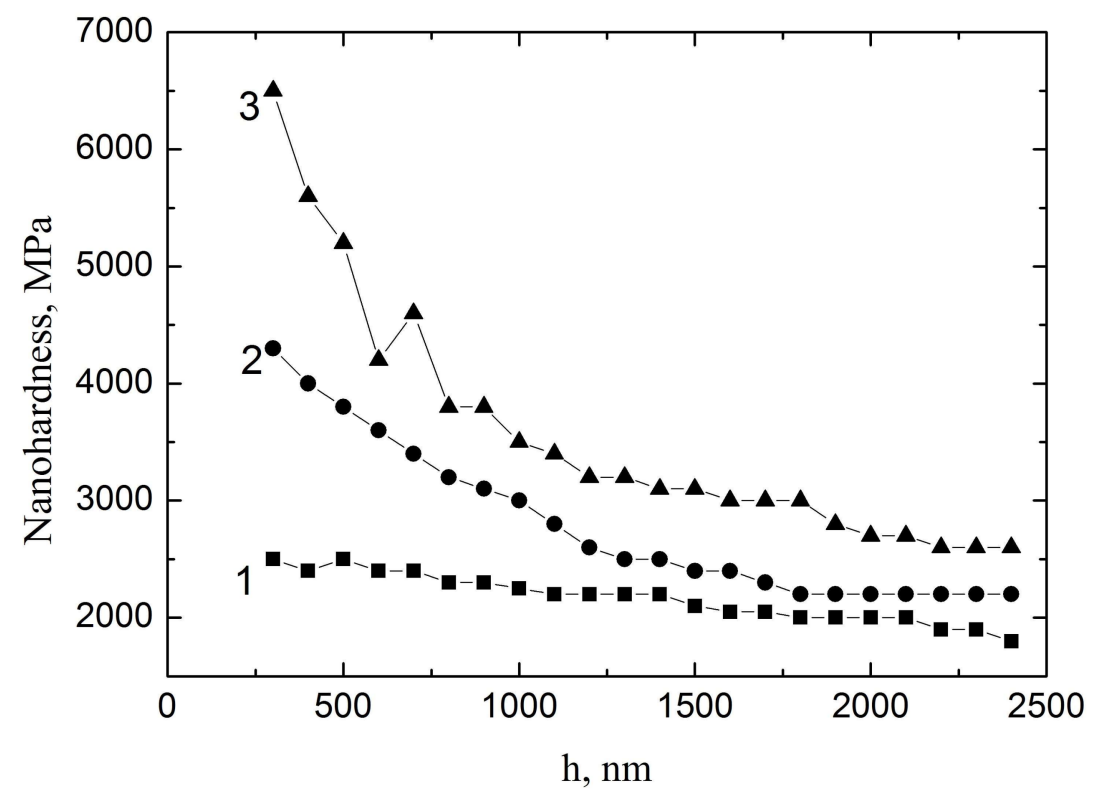

Figure 3. Nanohardness of the $\mathrm{Zr}-1 \mathrm{Nb}$ zirconium alloy hydrogenated from the gas phase, depending on the penetration depth ( 1 is the initial zirconium alloy; 2 is the hydrogenated zirconium alloy for $30 \mathrm{~min} ; 3$ is the hydrogenated zirconium alloy for $60 \mathrm{~min}$ ).

At a depth of about $300 \mathrm{~nm}$, it grows from $2600 \mathrm{MPa}$ (for the initial sample) to $6700 \mathrm{MPa}$. A decrease in nanohardness is observed with increasing the depth. For the samples saturated for $30 \mathrm{~min}$, the nanohardness value is decreased and becomes equal to the nanohardness of the initial material at a depth of about $2 \mu \mathrm{m}$. At the same time, the nanohardness of the samples hydrogenated for $60 \mathrm{~min}$ is $30 \%$ higher than that of the initial sample at this depth. This is connected with the fact that the proportion of hydride phases in the surface layer of the zirconium alloy is increased with increasing the saturation time $[35,36]$.

The microhardness of the zirconium alloy (initial and not hydrogenated, $1300 \mathrm{MPa}$ ) hydrogenated from the gas phase for $30 \mathrm{~min}$ is $2400 \mathrm{MPa}$ and $2700 \mathrm{MPa}$ (Table 2) for $60 \mathrm{~min}$. After electron beam irradiation for the release of hydrogen, the microhardness is increased up to $3200 \mathrm{MPa}$. It should be noted that during electrolytic saturation, the microhardness is two times less and is equal to $1500 \mathrm{MPa}$. The change in the mechanical properties of the hydrogenated zirconium alloy during 
electron irradiation is explained by several mechanisms of hydrogen release. For example, during electrolysis, hydrogen is concentrated in the near-surface layer in contrast to hydrogenation from the gas phase. The thickness of this layer is approximately equal to the track of electrons. Therefore, there is an excess of electrons and a lack of protons in this layer. The gradients of the hydrogen concentration and electric and magnetic fields are created, which has an effect on mechanical properties. As a result, the flux of hydrogen in the zirconium layer saturated with different methods is different. Additionally, during irradiation, the potential barrier for the release of hydrogen from the sample is decreased. All the discussed facts are likely to lead to a decrease in microhardness during electrolytic saturation in comparison with gas saturation. Apparently, this is also referred to the relation between microhardness and tensile strength.

Table 2. Microhardness of the zirconium alloy hydrogenated from the gas phase.

\begin{tabular}{ccccccc}
\hline Type of Treatment & \multicolumn{3}{c}{ No Irradiation } & \multicolumn{3}{c}{ Electron Beam } \\
\hline Time of treatment & initial & $30 \mathrm{~min}$ & $60 \mathrm{~min}$ & initial & $30 \mathrm{~min}$ & $60 \mathrm{~min}$ \\
Microhardness, MPa & 1300 & 2500 & 2700 & 2160 & 3100 & 3200 \\
\hline
\end{tabular}

In addition, an increase in the microhardness of the samples is due to both an increase in internal stress during the introduction of hydrogen and the formation of hydride phases. As follows from Table 2, after hydrogenation from the gas phase, the hardening is observed for the initial (not hydrogenated) alloy sample during hydrogenation and for the hydrogenated $\mathrm{Zr}-1 \mathrm{Nb}$ alloy during electron irradiation. The sample testing results for different conditions are shown in Figure 4.

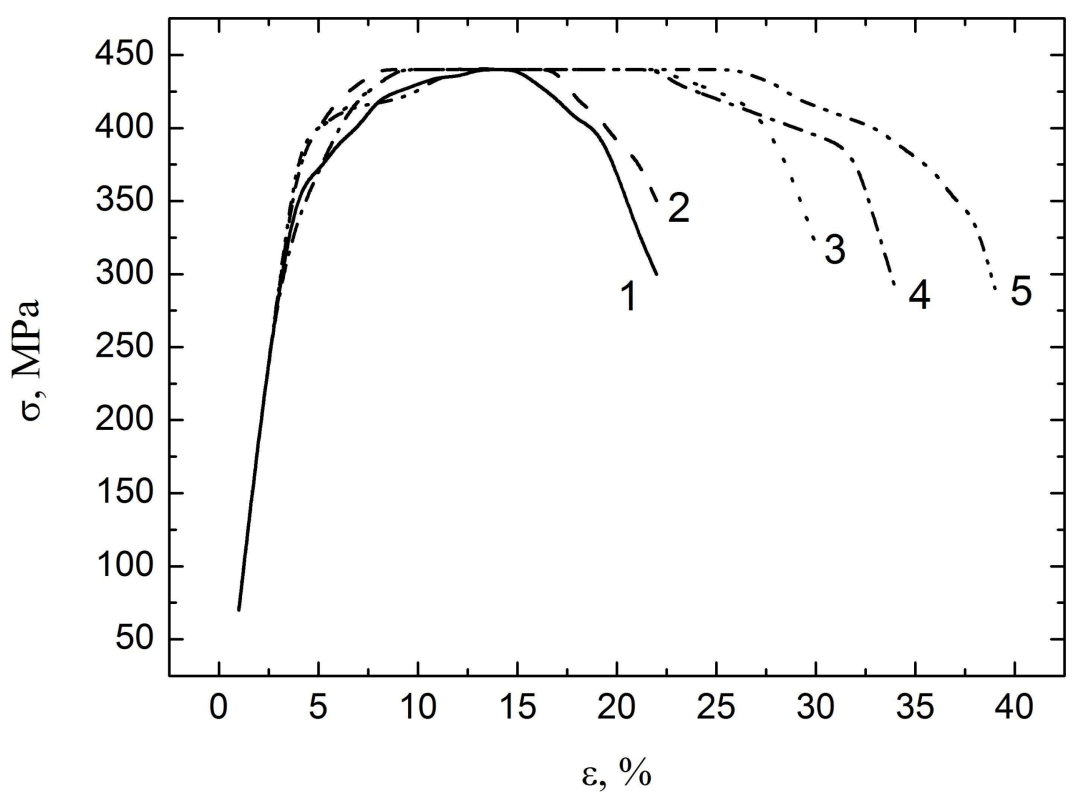

Figure 4. Stress-strain curves for the $\mathrm{Zr}-1 \mathrm{Nb}$ zirconium alloy: 1 is the zirconium alloy hydrogenated by the gas method to a concentration of $0.07 \mathrm{wt} \% ; 2$ is the zirconium alloy hydrogenated to a concentration of $0.035 \mathrm{wt} \% ; 3$ is the sample after the thermal removal of hydrogen; 4 is the $\mathrm{Zr}-1 \mathrm{Nb}$ initial (not hydrogenated) sample, 5 is the zirconium alloy after electron beam irradiation and removal of hydrogen.

Figure 4 shows that the higher plasticity of the samples is observed during electron irradiation compared to the plasticity of the samples subjected to thermal heating. Perhaps this is due to the fact that electron beam irradiation leads to the partial annealing of defects by inducing the disintegration of defect complexes (including hydrides) followed by the desorption of hydrogen. 


\section{Conclusions}

1. The results have shown that the strain of the zirconium alloy depends on the method for hydrogen removal from the alloy. Plasticity is slightly changed in the range of hydrogen concentrations from 0.035 to $0.07 \mathrm{wt} \%$. After the thermal removal of hydrogen, plasticity is increased by $30-40 \%$.

2. Plasticity is increased by $70-80 \%$ when the hydrogen release is stimulated by electron beam irradiation, which is connected with the partial annealing of defects followed by the desorption of hydrogen.

3. Hydrogenation of the alloy leads to the formation of traps, which was found by the peak position of gas release. The peak displacement between RSHR and from the TSHR is about $300{ }^{\circ} \mathrm{C}$.

4. The activation energy of hydrogen release was calculated for various heating rates of the hydrogenated zirconium samples. The calculations have shown that the activation energy varies from $1.3 \mathrm{eV}$ to $2.5 \mathrm{eV}$.

5. The microhardness of the zirconium alloy (the initial sample before hydrogenation) is $1300 \mathrm{MPa}$, hydrogenated from the gas phase for $30 \mathrm{~min}$ is $2400 \mathrm{MPa}$ and $2700 \mathrm{MPa}$ for $60 \mathrm{~min}$. After electron beam irradiation conducted to remove hydrogen from the alloy, the microhardness is increased up to $3200 \mathrm{MPa}$. The microhardness is two times less after electrolytic saturation and is about $1500 \mathrm{MPa}$.

6. The results of the investigation can be useful for a case in which there is a need for the removal of hydrogen and hardening of zirconium products using low-current electron beams, for example, small-scale betatron currents.

Acknowledgments: The research is carried out within the framework of the grant of the Program for Enhancing Competitiveness of Tomsk Polytechnic University. The research is funded by the Governmental program "Science", research project No. 11.3683.2017/4.6.

Author Contributions: Vitaliy V. Larionov carried out mechanical testing, analyzed the results and prepared the paper. Yuri I. Tyurin performed hydrogen removal by an electron beam and thermal heating, analyzed the results and prepared the paper. Viktor N. Kudiiarov performed hydrogenation of samples, revised the manuscript and directed the work.

Conflicts of Interest: The authors declare no conflict of interest.

\section{References}

1. Fukai, Y. The Metal-Hydrogen System; Springer: Berlin/Heidelberg, Germany; New York, NY, USA, 2005; Volume 21.

2. Puls Manfred, P. The Effect of Hydrogen and Hydrides on the Integrity of Zirconium Alloy Components: Delayed Hydride Cracking; MPP Consulting: Oakville, ON, Canada; Springer: London, UK, 2012; 451p.

3. Pundt, A.; Kirchheim, R. Hydrogen in metals: Microstructural aspects. Annu. Rev. Mater. Res. 2006, 36, 555-608. [CrossRef]

4. Zielinski, A.; Sobieszczyk, S. Hydrogen-enhanced degradation and oxide effects in zirconium alloys for nuclear applications. Int. J. Hydrogen Energy 2011, 36, 8619-8629. [CrossRef]

5. Kashkarov, E.B.; Nikitenkov, N.N.; Sutygina, A.N.; Syrtanov, M.S.; Vilkhivskaya, O.V.; Pryamushko, T.S.; Kudiiarov, V.N.; Volesky, L. Effect of titanium ion implantation and deposition on hydrogenation behavior of $\mathrm{Zr}-1 \mathrm{Nb}$ alloy. Surf. Coat. Technol. 2016, 308, 2-9. [CrossRef]

6. Azevedo, C.R.F. Selection of fuel cladding material for nuclear fission reactors. Eng. Fail. Anal. 2011, 18, 1943-1962. [CrossRef]

7. Hallstadius, L.; Johnson, S.; Lahoda, E. Cladding for performance fuel. Progr. Nucl. Energy 2012, 57, 71-76. [CrossRef]

8. Nagase, F. Hydride behavior in Zircaloy cladding tube during high-temperature transients. J. Nucl. Mater. 2011, 415, 117-122. [CrossRef]

9. Lider, A.M.; Pushilina, N.S.; Kudiiarov, V.N.; Kroening, M. Investigation of hydrogen distribution from the surface to the depth in technically pure titanium alloy with the help of glow discharge optical emission spectroscopy. Appl. Mech. Mater. 2013, 302, 92-96. [CrossRef] 
10. Motta, A.T.; Chen, L.Q. Hydride formation in zirconium alloys. J. Miner. Met. Mater. Soc. 2012, 64, $1403-1408$. [CrossRef]

11. Nagase, F.; Fuketa, T. Investigation of hydride rim effect on failure of Zircaloy-4 cladding with tube burst test. J. Nucl. Sci. Technol. 2005, 42, 58-65. [CrossRef]

12. Hanson, B.; Shimskey, R.; Lavender, C.; MacFarlan, P.; Eslinger, P. Hydride Rim Formation in Unirradiated Zircaloy. Available online: https://www.energy.gov/sites/prod/files/2013/08/f2/ HydrideRimFormationZircaloy.pdf (accessed on 22 March 2018).

13. Shimskey, R.; Hanson, B.; MacFarlan, P. Optimization of Hydride Rim Formation in Unirradiated Zr-4 Cladding. Available online: https://www.pnnl.gov/main/publications/external/technical_reports/PNNL22835.pdf (accessed on 22 March 2018).

14. Steinbruck, M. Hydrogen absorption by zirconium alloys at high temperatures. J. Nucl. Mater. 2004, 334, 58-64. [CrossRef]

15. Huang, J.-H.; Yeh, M.-S. Gaseous hydrogen embrittlement of a hydrided zirconium alloy. Metall. Mater. Trans. A 1998, 29, 1047-1056. [CrossRef]

16. Terrani, K.A.; Balooch, M.; Wongsawaeng, D.; Jaiyen, S.; Olander, D.R. The kinetics of hydrogen desorption from and adsorption on zirconium hydride. J. Nucl. Mater. 2010, 397, 61-68. [CrossRef]

17. Kammenzind, B.K.; Berquist, B.M.; Bajaj, R. The long-range migration of hydrogen through ziicaloy in response to tensile and compressive stress gradients. In Zirconium in the Nuclear Industry: Twelfth International Symposium; ASTM STP 1354; ASTM International: West Conshohocken, PA, USA, 2000; pp. 196-233.

18. Shmakov, A.A.; Smirnov, E.A.; Bruchertseifer, H. Hydrogen diffusion and distribution in oxidized zirconium alloys by thermo-release method. Metallofiz. Noveishie Technol. 1999, 21, 35-39. (In Russian)

19. Kim, Y.S.; Matvienko, Y.G.; Cheong, Y.M.; Kim, S.S.; Kwon, S.C. A model of the threshold stress intensity factor $\mathrm{KiH}$ for delayed hydride cracking of Zr-2,5Nb alloy. J. Nucl. Mater. 2000, 278, 251-257. [CrossRef]

20. Shi, S.Q. Diffusion-controlled hydride growth near crack tip in zirconium under temperature transients. J. Nucl. Mater. 1999, 275, 318-323. [CrossRef]

21. Sickafusa, K.E.; Matzkeb, H.J.; Hartmanna, T.H.; Yasudac, K.; Valdeza, J.A.; Chodak, P.; Nastasia, M.; Verralle, R.A. Radiation damage effects in zirconia. J. Nucl. Mater. 1999, 274, 66-77. [CrossRef]

22. Puis, M.P. The effects of misfit and external stresses on terminal solid solubility in hydride-forming metals. Acta Metall. 1981, 29, 1961-1968. [CrossRef]

23. Puis, M.P. Elastic and plastic accommodation effects on metal-hydride solubility. Acta Metall. 1984, 32, 1259-1269. [CrossRef]

24. Dupin, N.I.; Ansara, I.; Servant, C.; Toffolon, C.; Lemaignan, C.; Brachet, J.C. A thermodynamic database for zirconium alloys. J. Nucl. Mater. 1999, 275, 287-295. [CrossRef]

25. Ambler, J.F.R. Effect of direction of approach to temperature on the delayed hydrogen cracking behavior of cold-worked Zr-2,5Nb. In Zirconium in the Nuclear Industry; ASTM STP 824; ASTM International: West Conshohocken, PA, USA, 1984; pp. 653-674.

26. Sagat, S.; Chow, C.K.; Puls, M.P.; Coleman, C.E. Delayed hydride cracking in zirconium alloys in a temperature gradient. J. Nucl. Mater. 2000, 279, 107-117. [CrossRef]

27. Sawatzky, A.; Ells, C.E. Understanding hydrogen in zirconium. In Zirconium in the Nuclear Industry: Twelfth International Symposium; ASTM STP 1354; ASTM International: West Conshohocken, PA, USA, 2000; pp. 32-48.

28. Wappling, D.; Massih, A.R.; Stable, P. A model for hydride induced embrittlement in zirconium-based alloys. J. Nucl. Mater. 1997, 249, 231-238. [CrossRef]

29. Yamanakaa, S.; Yoshiokaa, K.; Unoa, M.; Katsuraa, M.; Anadab, H.; Matsudac, T.; Kobayashic, S. Thermal and mechanical properties of zirconium hydride. J. Alloys Compd. 1999, 293-295, 23-29. [CrossRef]

30. Kaneda, A.; Yamamoto, M.; Naito, S.; Mabuchi, M.T.; Hashino, T. Electrical resistivity of zirconium hydrides and deuterides at high temperatures. J. Phys. Condens. Matter 1998, 10, 4645. [CrossRef]

31. Tomiyasu, K.; Sugiyama, T.; Fuketa, T. Influence of cladding-peripheral hydride on mechanical fuel failure under reactivity-initiated accident conditions. J. Nucl. Sci. Technol. 2007, 44, 733-742. [CrossRef]

32. Tsuchiya, B.; Teshigawara, M.; Konara, K.; Nagata, S.; Shikama, T.; Yamawaki, M. Isotope Effects in Thermal Diffusivity and Electrical Resistivity of Zirconium Hydride and Deuteride. J. Nucl. Sci. Technol. 2002, 39, 402-406. [CrossRef] 
33. CSA. Technical Requirements for the In-Service Evaluation of Zirconium Alloy Pressure Tubes in CANDU Reactors; Nuclear Standard N 285.8-10; Canadian Standards Association: Mississauga, ON, Canada, 2010.

34. Tyurin, Y.I.; Nikitenkov, N.N.; Sigfusson, I.T.; Hashhash, A.; Yaomin, V.; Dolgov, A.S.; Semkina, L.I. Diffusion and release of hydrogen from metals under the effect of ionizing radiation. Vacuum 2016, 131, 73-80. [CrossRef]

35. Voskuilen, T.Y.; Zheng, Y.; Pourpoint, T. Development of a Sievert apparatus for characterization of high hydrogen sorption materials. Int. J. Hydrogen Energy 2010, 35, 10387-10395. [CrossRef]

36. Tyurin, Y.I.; Larionov, V.V.; Nikitenkov, N.N. A laboratory device for measuring the diffusion coefficient of hydrogen in metals during their simultaneous hydrogenation and electron irradiation. Instrum. Expert Tech. 2016, 59, 772-774. [CrossRef]

37. Kan, Q.; Yan, W.; Kang, G.; Sun, Q. Oliver-Pharr indentation method in determining elastic moduli of shape memory alloys-A phase transformable material. J. Mech. Phys. Solids 2013, 61, 2015-2033. [CrossRef]

38. Woodrouff, D.P.; Delchar, T.A. Modern Techniques of Surface Science, 2nd ed.; Cambridge University Press: Hongkong, China, 1994.

39. Bhushan, B. (Ed.) Springer Handbook of Nanotechnology; Springer: Berlin, Germany, 2007.

(C) 2018 by the authors. Licensee MDPI, Basel, Switzerland. This article is an open access article distributed under the terms and conditions of the Creative Commons Attribution (CC BY) license (http:/ / creativecommons.org/licenses/by/4.0/). 